\title{
THE NEPHROTOXICITY OF CONCURRENT USE OF ENALAPRIL AND GENTAMICIN IN RATS
}

\author{
IMAD M AL-ANI ${ }^{1}$, KHALEED R ALGANTRI ${ }^{2}$, EMAD M NAFIE ${ }^{1}$, SINAN MOHAMMED ABDULLAH AL-MAHMOOD ${ }^{3 *}$
}

${ }^{1}$ Department of Basic Medical Sciences, Kulliyyah of Medicine, International Islamic University Malaysia, Kuantan, Malaysia. ${ }^{2}$ Department of Basic Medical Sciences, Widad University College, Kuantan, Malaysia. ${ }^{3}$ Department of Basic Medical Sciences, Kulliyyah of Nursing, International Islamic University Malaysia, Kuantan, Malaysia. Email:sinan.almawla@gmail.com

Received: 25 April 2018, Revised and Accepted: 31 May 2018

ABSTRACT

Objective: The present study was aimed to assess the concurrent administration of Enalapril (ENAL) and Gentamicin (GM) in the kidney of rats.

Methods: Sixty male Sprague Dawley rats were divided into 4 main groups $(n=15)$ according to the administered dose. Each main group was further subdivided into three subgroups according to the day of sacrificing ( $\mathrm{n}=5$ ). Group (C) was administered daily with normal saline as control, Group (E) was treated with oral ENAL, Group (G) was treated with $75 \mathrm{mg} / \mathrm{kg} \mathrm{GM}$, and Group (EG) was treated with GM and ENAL. The handling of the experiment persisted daily for 15 days, and the investigational examination carried out on days 5, 10, and 15 .

Results: The result showed that GM nephrotoxicity augmented with the period of the experimental study, there was rising in the levels of serum creatinine and blood urea nitrogen on the $10^{\text {th }}$ day and persisted in rising significantly during the period on the $15^{\text {th }}$ day of the experiment. Administration of ENAL showed no significant alteration from those of controls. While the concurrent administration of ENAL and GM showed that ENAL gradually increased GM nephrotoxicity, these physiological retrogressions were accompanied with intensive renal histopathological deteriorations.

Conclusion: The present study has revealed that the concurrent administration of ENAL enormously aggravated the functional and histological nephrotoxicity of GM in rats.

Keywords: Nephrotoxicity, Concurrent, Enalapril, Gentamicin.

(C) 2018 The Authors. Published by Innovare Academic Sciences Pvt Ltd. This is an open access article under the CC BY license (http://creativecommons. org/licenses/by/4. 0/) DOI: http://dx.doi.org/10.22159/ajpcr.2018.v11i9.26853

\section{INTRODUCTION}

Nephrotoxicity can be defined as renal disease or dysfunction that arises as a direct or indirect result of exposure to medicines and industrial or environmental chemicals [1]. Gentamicin (GM) is an aminoglycoside antibiotic derived from a group of common soil microorganisms that are used in the treatment of severe infections [2]. Prolonged therapies with high dosages of GM evolve signs and symptoms of nephrotoxicity [3]. The GM nephrotoxicity display renal inflammatory process and oxidative stress in humans [4] and rats [5,6]. It has been established that GM nephrotoxicity is a dangerous circumstance distinguished by elevated serum creatinine and blood urea nitrogen (BUN) levels and enormous renal tubular necrosis, followed by worsening and renal failure [7].

Angiotensin-converting enzyme inhibitors (ACEI) are medications used primarily for the management of acute and chronic elevated blood pressure, left ventricular dysfunction and heart failure, and chronic kidney disease [8]. One study highlighted the importance of ACEI in the management of hypertension with proteinuria [9]. Enalapril (ENAL) is a long-acting ACEI, used in hypertension and heart failure, and has been shown to lower the death rate in systolic heart failure [10]; and preserve renal function through inhibiting the vasoconstrictive effects of angiotensin II at the efferent arteriole by reducing the concentration of angiotensin II or by blocking its receptor [11]. Experimental studies have shown that ENAL, improved systemic and renal hemodynamics and the intrarenal glomerular dynamics [12].

The effects of ACEI on GM nephrotoxicity are controversial. Captopril has been found to, potentiated GM-induced nephrotoxicity by increasing serum creatinine and urea concentrations and inducing severe necrosis of proximal convoluted tubule (PCT) [13]. However, captopril has been demonstrated to have a beneficial role in protecting GM-induced nephropathy $[14,15]$. The present study was designed to conclude whether ENAL would alter the pathophysiological changes induced in the kidney by GM.

\section{METHODS}

Animals and experimental design

The present study was carried out with the approval of the Institutional Animal Care and Use Committee of the International Islamic University of Malaysia (IACUC, IIUM). Animals of white, male, Sprague Dawley rats of 10-12 weeks old and body weight 250-300 g were used in this investigation. After acclimation to suitable laboratory conditions in animal facilities such as room temperature $\left(24 \pm 4^{\circ} \mathrm{C}, 50 \%\right.$ - relative air humidity, and $12: 12 \mathrm{~h}$ light and dark cycles); had free access to laboratory standard pellet diet and water ad libitum. 60 rats were distributed into four main groups $(n=15)$ according to the dosage of administered drug (Table 1). Each group was then subdivided into three subgroups according to the sacrificing day $(n=5)$.

\section{Chemicals}

Gentamicin (GM) sulfate powder was purchased from (SANOFI) corporation. It was dissolved in distilled water and used as a single intraperitoneal dose of $75 \mathrm{mg} / \mathrm{kg} /$ day. ENAL maleate was purchased from Sigma and dissolved in distilled water; the rats treated daily an oral dose of $2 \mathrm{mg} / \mathrm{kg}$ using a syringe and metal ball-ended needle.

\section{Biochemical analysis}

Blood samples were collected by ventricular puncture, in plastic tubes, centrifuged, and the plasma was stored at $-80^{\circ} \mathrm{C}$ until used for biochemical analysis. Serum creatinine and BUN analysis were performed according to the kinetic Jaffe method.

\section{Histopathological study}

Cervical dislocation was performed under light anesthesia at the end of the $5^{\text {th }}, 10^{\text {th }}$, and $15^{\text {th }}$ days of the experimental studies. The kidneys were rapidly excised, fixed in $10 \%$ formal saline for $72 \mathrm{~h}$; dehydrated successively in $70 \%, 90 \%, 95 \%$, and $100 \%$ ethanol, cleared in xylene, and embedded in paraffin wax. Paraffin sections of 4-5 $\mu \mathrm{m}$ thickness 
Table 1: Distribution of animals by groups

\begin{tabular}{llc}
\hline Groups (15 rats/group) & \multicolumn{2}{l}{ Sub Groups (5 rats/subgroup) } \\
\hline C: Normal saline (1 ml/day, i.p.) & C1: Killed on day 5 & C2: Killed on day 10 \\
E: ENAL (2 mg/kg/day, i.p.) & E1: Killed on day 5 & E2: Killed on day 10 \\
G: GM (75 mg/kg/day, i.p.) & G1: Killed on day 5 & G2: Killed on day 10 \\
EG: ENAL (2 mg/kg/day, i.p.)+GM (75 mg/kg/day, i.p.) & EG1: Killed on day 5 & EG2: Killed on day 10 \\
\hline
\end{tabular}

ENAL: Enalapril

Table 2: Blood urea nitrogen (mmol/L) and serum creatinine (umol/L) in the studied groups

\begin{tabular}{|c|c|c|c|c|c|c|}
\hline \multirow{2}{*}{$\frac{\text { Groups }}{\text { Groups/Day }}$} & \multicolumn{3}{|c|}{ Blood urea nitrogen (mmol/L) } & \multicolumn{3}{|c|}{ Serum creatinine (umol/L) } \\
\hline & Day 5 & Day 10 & Day 15 & Day 5 & Day 10 & Day 15 \\
\hline $\mathrm{C}$ & $7.6 \pm 0.6$ & $7.6 \pm 0.7$ & $7.9 \pm 0.6$ & $26 \pm 3$ & $30.9 \pm 4.2$ & $41.6 \pm 9$ \\
\hline E & $6.9 \pm 1.2$ & $7.9 \pm 1.1$ & $8.4 \pm 0.5$ & $27.53 \pm 3.5$ & $46.8 \pm 3.6$ & $68.4 \pm 19.9$ \\
\hline $\mathrm{G}$ & $12.65 \pm 7.53$ & $13.2 \pm 5.7^{*}$ & $16.06 \pm 6.7^{*}$ & $59.4 \pm 23.8^{*}$ & $92 \pm 8.8^{*}$ & $95.2 \pm 10.7^{*}$ \\
\hline EG & $13.3 \pm 1.1$ & $86.5 \pm 11.2^{* *}$ & $97.5 \pm 17.5^{* *}$ & $53 \pm 20.8$ & $116 \pm 18.7^{* *}$ & $754.2 \pm 184.5^{* *}$ \\
\hline
\end{tabular}

Values are expressed as mean \pm SEM. $P$ values: *Significantly $(\mathrm{p}<0.05)$ different from control group, ${ }^{* *}$ Highly significantly ( $\left.<<0.01\right)$ different from Gentamicin group. The statistical test employed was ANOVA, followed by a post hoc test (Tukey's HSD), $n=5$ in each group

were stained with Hematoxylin and Eosin. Evaluation of the kidney sections was performed blindly by two independent histopathologists.

\section{Statistical analysis}

Statistical analysis was performed using the SPSS version 20 . The values were represented as mean \pm SEM. A One-way Analysis of Variance (ANOVA) test was used and followed by a post hoc test (Tukey's HSD); significance was set to $\mathrm{p}<0.05$ being considered as significant and $\mathrm{p}<0.05$ as highly significant.

\section{RESULTS}

All experimental rats were vital and in good health; no mortality was noted throughout the duration of the investigation; nevertheless, the EG group rats showed irritating behavior.

\section{Biochemical analysis}

The current research revealed that the GM treated rats, and GM together with ENAL for $(5,10$, and 15) days lead to a significant $(\mathrm{p}<0.05)$ elevation in the concentrations of the serum creatinine and BUN when compared to the control rats. ENAL administration to the rats did not induce any remarkable alteration in the quantities of serum creatinine and BUN. Rats injected with GM produced a non-significant $(\mathrm{p}>0.05)$ elevation in BUN $(12.65 \pm 7.53 \mathrm{mmol} / \mathrm{L})$ and a significant $(\mathrm{p}<0.05)$ rise in serum creatinine level $(59.4 \pm 23.8 \mathrm{umol} / \mathrm{L})$ on the $5^{\text {th }}$ day. A significant elevation $(\mathrm{p}<0.05)$ in BUN $(13.2 \pm 5.7 \mathrm{mmol} / \mathrm{L})$ and serum creatinine $(92 \pm 8.8 \mathrm{umol} / \mathrm{L})$ compared to control were observed on the $10^{\text {th }}$ day. On the $15^{\text {th }}$ day of treatment, more deterioration of renal function was observed; there was a significant increase in BUN (16.06 $\pm 6.7 \mathrm{mmol} / \mathrm{L})$ as well as a significant increase in serum creatinine (95.2 $\pm 10.7 \mathrm{umol} / \mathrm{L})$.

The concomitant administration of GM with ENAL for 5 days showed a non-significant $(\mathrm{p}>0.05)$ increase in BUN $(13.3 \pm 1.1 \mathrm{mmol} / \mathrm{L})$ and serum creatinine level $(53 \pm 20.8 \mathrm{umol} / \mathrm{L})$ compared to GM treated group. Treatment with both drugs for 10 days induced a high significant $(\mathrm{p}<0.01)$ increase in BUN $(86.5 \pm 11.2 \mathrm{mmol} / \mathrm{L})$ and serum creatinine level $(116 \pm 18.7 \mathrm{umol} / \mathrm{L})$; further treatment for $15^{\text {th }}$ day also showed a high significant $(\mathrm{p}<0.01)$ increase in BUN $(97.5 \pm 17.5 \mathrm{mmol} / \mathrm{L})$ and serum creatinine level $(754.2 \pm 184.5 \mathrm{umol} / \mathrm{L})$ compared to GM treated group (Table 2 ).

\section{Histological observation}

Analysis of $\mathrm{H}$ and $\mathrm{E}$ stained sections of kidneys from the control group (C group) showed normal histological architectures of the renal corpuscles, and renal tubules (Fig. 1a and b). Assessment of the kidneys sections of ENAL group (E group) demonstrated preservation of the renal cortex and medulla without any apparent histological alterations in the glomeruli and the renal tubules during the whole period of the treatment (Fig. 1c and d).
GM treatment (G group) gave rise to noticeable histopathological changes in the kidney tissues; the severity of these changes was increased with the increased period of GM exposure. On the $5^{\text {th }}$ day of the investigation (G1 group), the rats exhibited no apparent histopathological alteration.

The earliest histological deterioration changes in the cortical tissue were observed on the $10^{\text {th }}$ day (G2 group); these changes consist of shrinkage of the glomeruli, expansion of the Bowman's space; and an increase of the mesangial cells. In addition, dilation of numerous PCT and distal convoluted tubule, many cells of the PCT became visible with vacuolated cytoplasm and others had pyknotic nuclei; furthermore, many congested blood vessels were observed (Fig. 2a).

The histological changes in the kidneys of G3 group rats were more severe and extended to the renal papillae after 15 days of treatment. The cortex exhibited further shrinkage of the glomeruli and unorganized expansion of the Bowman's space beside to mesangial cell proliferation, and congestion of the capillaries. Furthermore, numerous PCT was injured showing tubular dilatation with vacuolar and cloudy epithelial cells lining, many PCT appeared particularly deprived of their lining epithelial cells, with only a bare basement membrane still existing; on the other hand, some PCT cells appeared disrupted with vacuolated cytoplasm and damaged brush borders. Shed epithelial cells and their fragments were occasionally detected. Remarkable blood vessels congestion, interstitial edema, and mononuclear cell infiltration were observed surrounding blood vessels and renal corpuscles (Fig. 2b and c). This histological deterioration proceeded and extended into the renal papillae; the tubules exhibited worsening histopathological injuries, accompanied by the incidence of congested blood vessels and hyaline casts (Fig. 2d)

The concomitant administration of ENAL and GM in (EG groups) revealed several histopathological changes in renal corpuscles and the urinary tubules in comparison with GM administered rats; the severity of these changes augmented with the increased duration of drug exposure. After 5 days of treatment (EG1 group); there was a progressive pathological deterioration in the renal tissue in compression with those observed in GM treated group. The renal corpuscles showed shrinking of the glomeruli and expansion of the Bowman's space and increased mesangial cells; the epithelial cells of PCT were necrotic, and cellular debris was observed in the tubular lumen correlated with mononuclear cells infiltration and congested blood vessels (Fig. 3a and b).

After 10 days of treatment, the kidneys of (EG2) group showed intense necrotic epithelial cells of PCT with hydropic alterations; the lumen of the expanded renal tubules was filled with desquamated epithelial cells and hyaline casts. The injured renal tubules were associated 
with distinguishable mononuclear cells infiltration and congested blood vessels (Fig. 4a and b). The damage was extended into the renal papilla; showing dilated tubules, some of them were filled with hyaline casts; these changes were associated with congested blood vessels (Fig. 4c).

With the advancement of concomitant treatment with GM and ENAL for 15 days (EG3 group); the renal parenchyma exhibited intensive retrogradation in renal corpuscles and tubular epithelium than those observed on the $10^{\text {th }}$ day (EG2 group). Shrunken glomerular tufts with distinguished hemorrhagic lesions concomitant with numerous mesangial cell were detected (Fig. $5 \mathrm{a}$ and b).

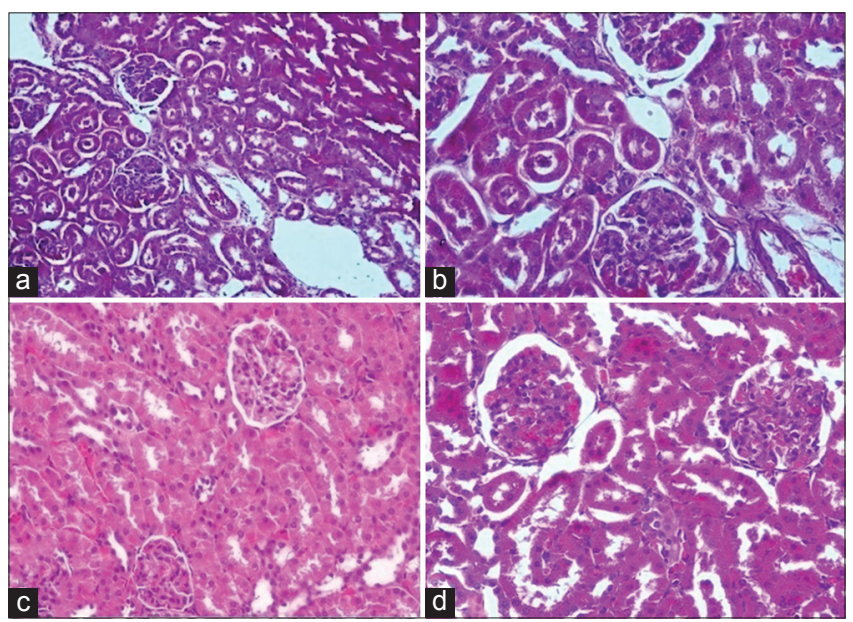

Fig. 1: (a and b) Control rat is showing normal histological structure of the glomerulus and architecture of tubules in the cortical portion. (c and d) Enalapril-treated rat kidney for 10 and 15 days, respectively, showing no pathological changes. $\mathrm{H}$ and $\mathrm{E}$. $X$ "A\&C 200," "B and D 400"

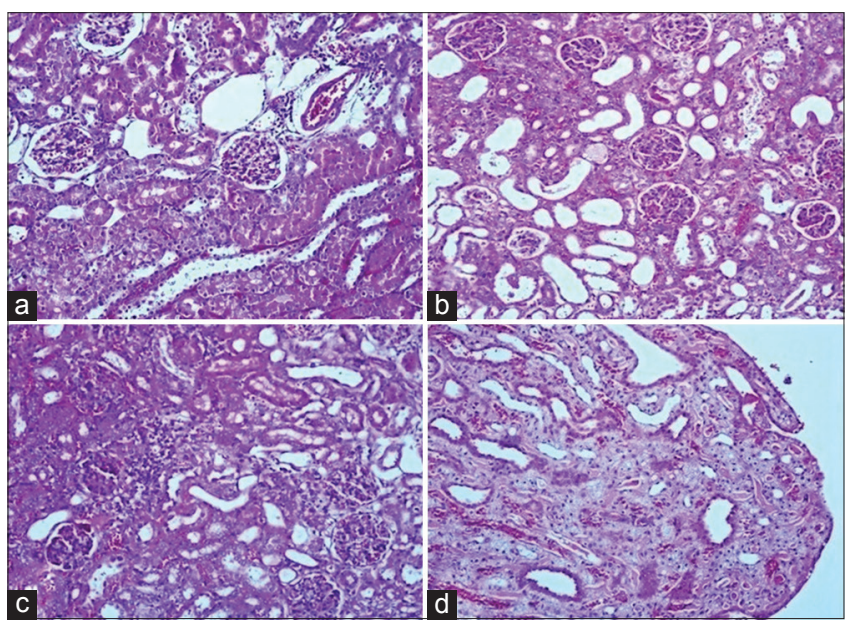

Fig. 2: (a) Gentamicin (GM) treated rat kidney for 10 days (G2) showing renal corpuscles with shrinkage of the glomeruli and widening of the Bowman's space, many PCT with the necrotic epithelial cell, presence congested blood vessels. (b and c) GM treated rat kidney for 15 days (G3) showing some renal corpuscles with shrinkage of the glomeruli, widening of the Bowman's space, capillary congestion and increased mesangial cells, many PCT with tubular dilatation and devoid of epithelial cells and mononuclear inflammatory cell infiltrates, and presence congested blood vessels. Furthermore, GM treated rat kidney for 15 days showing renal papilla with congested blood vessels, Tubular dilatation, hyaline casts (d). $\mathrm{H}$ and E. $\times 200$
The lining epithelial cells of the renal tubules revealed extensive histopathological changes characterized swelled and necrotic cells, destructed brush border of dilated PCT; congested capillaries and focal hemorrhage were observed between the deteriorated renal tubules. The tubular lumens were filled with desquamated cells, cell debris and hyaline eosinophilic material, in addition, mononuclear cellular infiltration was observed in the interstitial tissues (Fig. 5a and b). Considerable renal papillary necrosis with congested blood vessels; in addition, hyaline casts, granular eosinophilic debris, and desquamated necrotic tubular epithelial cells accompanied with interstitial mononuclear cell infiltration were found in the rats of this group (Fig. 5c).

\section{DISCUSSION}

Aminoglycosides mainly GM has long been known as a significant contributor to a kidney problem, it is the most distinctive sources of drug-induced nephrotoxicity [16]. Previous experimental researches attempted to minimize the toxic impact of GM on kidney by combining it with several medicines and remedies; Vitamin E and N-Acetyl Cysteine significantly restored renal functions in rats treated rats with $80 \mathrm{mg} /$ $\mathrm{kg} / 8$ days of GM [17]. Histopathological observation showed that Piperacillin has protective effects against the nephrotoxicity of GM in rabbits treated daily with $100 \mathrm{mg} / \mathrm{kg}$ GM for 5 days [18]. Moreover,

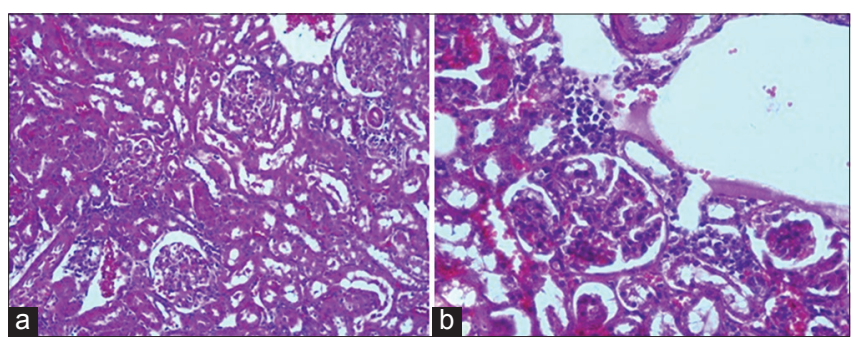

Fig. 3: (a and b) Gentamicin and Enalapril treated rat kidney (GE1) for 5 days showing renal corpuscles with shrinkage of the glomeruli, increased mesangial cells and widening of the Bowman's space, many PCT with necrotic epithelial cell and cast in the tubules, mononuclear infiltration, presence congested blood vessels. H and E. X “A 200," “B 400”

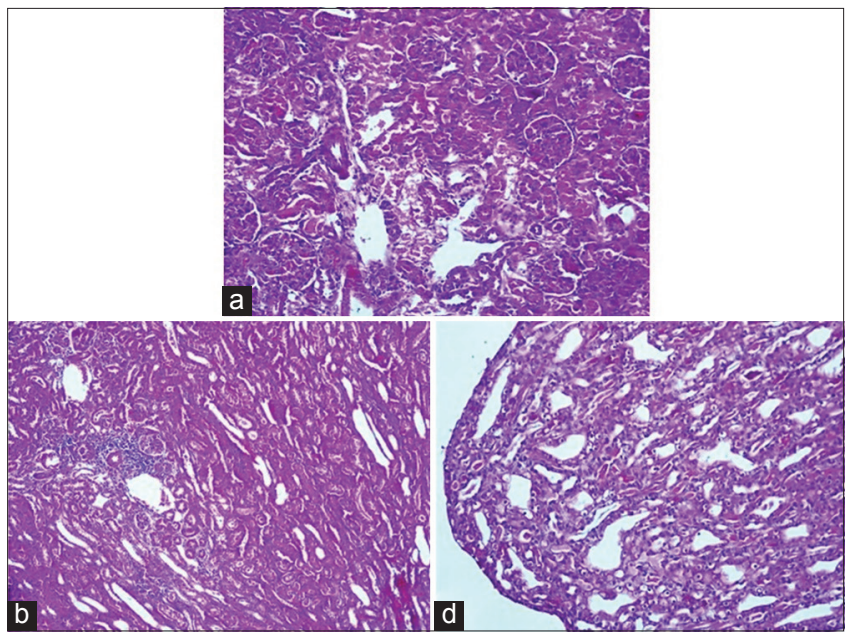

Fig. 4: (a and b) Gentamicin and Enalapril treated rat kidney (GE2) for 10 days showing renal corpuscles with more mesangial cells many PCT with necrotic epithelial cell and hydropic changes

and cast in the tubules, mononuclear infiltration presence congested blood vessels. (C) Renal papilla of (GE2) with congested blood vessels, tubular dilatation, and hyaline casts. $H$ and $E . \times 200$ 


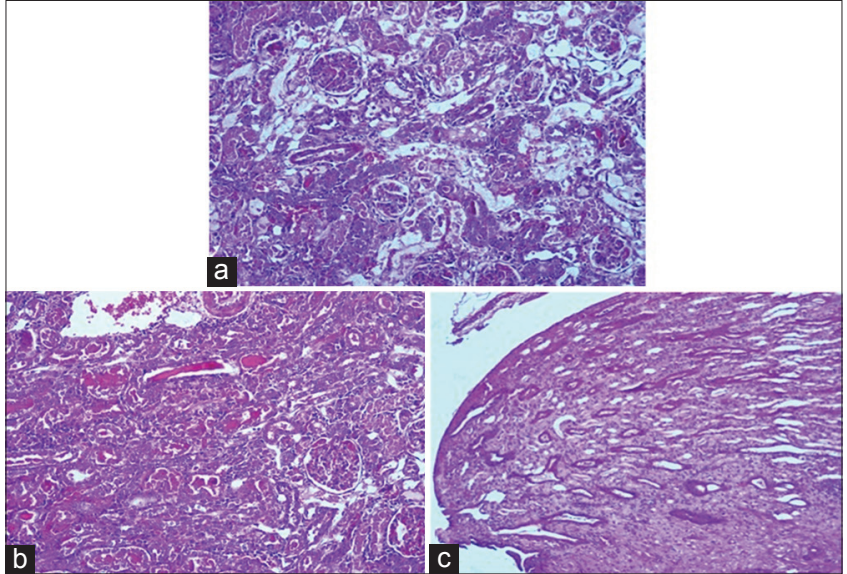

Fig. 5: (a and b) Gentamicin and Enalapril treated rat kidney (GE3) for 10 days showing renal corpuscles with shrunk glomeruli, increased mesangial cells and congested capillaries, severe necrotic PCT and hydropic change cast in the tubules.

(c) Necrotic renal papilla of (GE3) with congested blood vessels, tubular dilatation, hyaline casts and mononuclear infiltration. $\mathrm{H}$ and E. $\times 200$

Melatonin also reduced GM-induced nephrotoxicity in rats [19]. In contrast, other studies reported that the simultaneous administration of furosemide and GM might intensify GM-induced nephrotoxicity by reducing the volume of distribution of GM and increase the renal tubular absorption of GM and accelerate its accumulation in renal tissues [20]. The present investigation demonstrated that treatment with GM-induced physiological deterioration and morphological renal lesions; there was gradually increase of BUN and creatinine levels starting from the $5^{\text {th }}$ day toward the end of the experimentation on the $15^{\text {th }}$ day; this rising was commensurate with the duration of treatment; it is concordant with the increment of BUN demonstrated in rats administered with GM and amikacin [21]. Treatment of rats with $50 \mathrm{mg} / \mathrm{kg} /$ day of GM for 10 days [22], and for 15 days [4], indices significantly higher BUN and serum creatinine concentrations associated with renal injury in the glomeruli and tubular epithelial cells necrosis scores that proportionally increased with increasing doses of the antibiotic. In addition, short-term treatment with GM for 3 days or less has a very little prevalence of nephrotoxicity [23]. Conversely, longer duration of GM treatment "more than 2-week" is associated with worsening of renal function and resulted in a significantly greater decrease in glomerular filtration rate [24]. A gradual deterioration in kidney function was also observed in rats treated with $40 \mathrm{mg} / \mathrm{kg} \mathrm{GM}$ [25]. However, other studies have demonstrated that rats treated with $70 \mathrm{mg} / \mathrm{kg} \mathrm{GM}$ for 11 days did not reveal an increase in the level of the BUN, despite they develop a decline in creatinine clearance [26]. These contradicting outcomes outputs may be ascribed to the dosage of GM, species, and gender of the used experimental animals and to their usability toward nephrotoxicity through the inclination of GM toward the kidneys and to its accessibility to accumulate GM in the kidney cortical tissues.

In the present study, the gradual increase of BUN and creatinine levels throughout the period of this experimental study " $5{ }^{\text {th }}$ to the $15^{\text {th }}$ day" was associated with abnormal morphology of the renal tissue in the rats treated with GM. The incidence of the degenerative changes in the renal cortex was observed on the $10^{\text {th }}$ day of the treatment and continued throughout the rest period of the experiment progressing to the renal papillae on $15^{\text {th }}$ day; this observation is consistent with previous investigations that observed severe degenerative changes in renal glomeruli and necrosis of the PCT on the $10^{\text {th }}$ day and increased throughout the whole period of the study [27]. The mechanisms and consequences of nephrotoxicity induced by GM have not been established so far; the generation of reactive oxygen species, causing a deficiency in intrinsic antioxidant enzymes was suggested as a mechanism in the development of GM nephrotoxicity [28]. Induction of lipid peroxidation and mitochondrial hydrogen peroxide production were observed in the cortical renal tissue of rats treated with GM that leads to cellular degradation by denaturation of protein, peroxidation of lipids, and DNA destruction $[29,30]$.

The present investigation has shown that ENAL gradually augmented the retrogression of renal physiological activities stimulated by GM. The intense degenerative histological changes observed on the $5^{\text {th }}$ day and became severe and increased with the duration of drug exposure and extended to the renal papillae. There are controversial results regarding the outcome of the concomitant use of ACEI with GM; previous investigations using ACEI with GM indicated that ACEI might reduce or rise GM nephrotoxicity. Improvement in the functional deteriorations and renal damage induced by GM was observed after the administration of captopril that leads to suppression of progression of GM nephrotoxicity; this amelioration was related to the captopril potentiality to augmented bradykinin deliberation that leads to "vasodilator" which motivates prostaglandin production, ensuring an enlargement of the intrarenal blood vessels, and leading to an amelioration in the glomerular hemodynamic and preservation of the kidney from nephrotoxicity $[15,31]$. On the other hand, other studies have shown that ACEI increase GM nephrotoxicity, the concurrent treatment with perindopril and GM-induced a greater renal impairment than after the administration of GM alone [32], captopril has been found to increase GM nephrotoxicity and progressively decreased the creatinine clearance in rats [33], captopril also aggravated the detrimental consequence of GM on the renal function in rats depleted of potassium [13]. Captopril was also accompanied by a reduction of creatinine clearance and a decrease in excretion of cyclic GMP in hypertensive rats [34]. Furthermore, Patzer [35] detected that throughout ACEI commencement, renal dysfunction could take place due to a decline in renal perfusion pressure and subsequent reduction in glomerular filtration; this is due to vasodilation of the renal efferent arteriole, which minimizes the kidney's capacity to recompense for low perfusion conditions. Further structural, metabolic, functional, and clinical studies are needed to elucidate the mechanisms of the elevation effect of ENAL on the manifestations of GM nephrotoxicity.

\section{CONCLUSION}

The present study has revealed that the simultaneous administration of ENAL enormously aggravated the functional and histological nephrotoxicity of GM in rats.

\section{ACKNOWLEDGMENT}

This study was supported by International Islamic University Malaysia (RIGS 16-286-0450).

\section{CONFLICTS OF INTEREST}

The authors have no conflicts of interest to declare.

\section{AUTHOR'S CONTRIBUTION}

The authors declare that this work was done by the authors named in this article and all liabilities pertaining to claims relating to the content of this article will be borne by them.

\section{REFERENCES}

1. Karra G, Ramarao N, Sindhu B, Rao UV. Nephroprotective, nephrocurative activity of mimosa pudica root against gentamicin-induced nephrotoxicity. Int J Pharm Pharm Sci 2015;7:173-7.

2. Moulds RF, Jeyasingham MS. Gentamicin: A great way to start. Aust Prescr 2010;33:134-5.

3. Cuzzocrea S, Mazzon E, Dugo L, Serraino I, Di Paola R, Britti D, et al. A role for superoxide in gentamicin-mediated nephropathy in rats. Eur J Pharmacol 2002;450:67-76.

4. Kim SY, Moon A. Drug-induced nephrotoxicity and its biomarkers. Biomol Ther (Seoul) 2012;20:268-72. 
5. Kalayarasan S, Prabhu PN, Sriram N, Manikandan R, Arumugam M, Sudhandiran G, et al. Diallyl sulfide enhances antioxidants and inhibits inflammation through the activation of nrf 2 against gentamicin-induced nephrotoxicity in wistar rats. Eur J Pharmacol 2009;606:162-71.

6. Al-Attiyah ZM, Al-Ani IM, Abdul-Kareem HN, Matlop EI. The Effects of angiotensin-converting-enzyme inhibitor (Captopril) on gentamicin nephrotoxicity in rats. J Med Health Sci 2013;2:80-7.

7. Silan C, Uzun O, Comunoğlu NU, Gokçen S, Bedirhan S, Cengiz M, et al. Gentamicin-induced nephrotoxicity in rats ameliorated and healing effects of resveratrol. Biol Pharm Bull 2007;30:79-83.

8. Marbut MM, Rajab HK, Al-Mahmood SM. Significance of palpitation among hypertensive patients receiving captoprill. Med J Tikrit 2009; $15: 32-7$

9. Makmor-Bakry M, Hamdan N. Effect of angiotensin converting enzyme inhibitors and angiotensin-II receptor blockers on proteinuria of hypertensive patients in standard care practice. Int J Pharm Pharm Sci 2015;7:40-3.

10. Bhardwaj S, Balgir PP, Goel RK. Pharmacogenomics and personalized management of hypertension. J Critcal Rev 2015;2:1-6.

11. Delles C, Jacobi J, John S, Fleischmann I, Schmieder RE. Effects of enalapril and eprosartan on the renal vascular nitric oxide system in human essential hypertension1. Kidney Int 2002;61:1462-8.

12. Francischetti A, Ono H, Frohlich ED. Renoprotective effects of felodipine and/or enalapril in spontaneously hypertensive rats with and without L-NAME. Hypertension 1998;31:795-801.

13. Klotman PE, Boatman JE, Volpp BD, Baker JD, Yarger WE. Captopril enhances aminoglycoside nephrotoxicity in potassium-depleted rats. Kidney Int 1985;28:118-27.

14. Ali B, Bashir A. Comparative modulating effects of captopril, diltiazem, dietary calcium and pyridoxal-5'-phosphate on gentamicin-induced nephrotoxicity in the rat. Gen Pharmacol 1993;24:1279-83.

15. Chowdhury MS, Saha SK, Eva EO, Sarker MM. A study on the effect of captopril on gentamicin induced nephrotoxicity in rats. Mymensingh Med J 2018;27:57-67.

16. Walker PD, Barri Y, Shah SV. Oxidant mechanisms in gentamicin nephrotoxicity. Ren Fail 1999;21:433-42.

17. Patel Manali B, Deshpande S, Shah G. Evaluation of efficacy of vitamin $\mathrm{E}$ and $\mathrm{N}$-acetyl cysteine in gentamicin-induced nephrotoxicity in rats. Ren Fail 2011;33:341-7.

18. Hayashi T, Watanabe Y, Kumano K, Kitayama R, Yasuda T, Saikawa I, et al. Protective effect of piperacillin against nephrotoxicity of cephaloridine and gentamicin in animals. Antimicrob Agents Chemother 1988;32:912-8

19. Kumar KV, Naidu M, Shifow AA, Ratnakar K. Probucol protects against gentamicin-induced nephrotoxicity in rats. Indian $\mathrm{J}$ Pharmacol 2000;32:108-13

20. Nakahama H, Fukuhara Y, Orita Y, Yamauchi A, Takama T, Kamada T, et al. Furosemide accelerates gentamicin accumulation in cultured renal cells (LLC-PK1 cells). Nephron 1989;53:138-41.
21. Rankin LI, Luft FC, Yum MN, Sloan RS, Dinwiddie CB Jr., Isaacs LL, et al. Comparative nephrotoxicity of SCH 21420 and amikacin in rats. Antimicrob Agents Chemother 1979;16:491-4.

22. Dellinger P, Murphy T, Pinn V, Barza M, Weinstein L. Protective effect of cephalothin against gentamicin-induced nephrotoxicity in rats. Antimicrob Agents Chemother 1976;9:172-8.

23. Nicolau DP, Freeman CD, Belliveau PP, Nightingale CH, Ross JW, Quintiliani R, et al. Experience with a once-daily aminoglycoside program administered to 2,184 adult patients. Antimicrob Agents Chemother 1995;39:650-5

24. Dahl A, Rasmussen RV, Bundgaard H, Hassager C, Bruun LE, Lauridsen TK, et al. Enterococcus faecalis infective endocarditis: A pilot study on the relationship between duration of gentamicin treatment and outcome. Circulation 2013;127:1810-17.

25. Mandell GL, Bennett JE, Dolin R, Schwartz DA. Principles and practice of infectious disease. Arch Pathol Lab Med 1997;121:908.

26. Smetana S, Khalef S, Kopolovic G, Bar-Khayim Y, Birk Y, Kacew S, et al. Effect of interaction between gentamicin and pyridoxal-5-phosphate on functional and metabolic parameters in kidneys of female spraguedawley rats. Ren Fail 1992;14:147-53.

27. Al-Attiyah ZA. The Concomitant Effect of Gentamicin and Angiotensinconverting-Enzyme Inhibitors (Captopril) on the Renal Structure and Function. M.Sc. Thesis, Al-Mustansiriah University, Baghdad, Iraq; 1996.

28. Maldonado PD, Barrera D, Medina-Campos ON, Hernández-Pando R, Ibarra-Rubio ME, Pedraza-Chaverrí J, et al. Aged garlic extract attenuates gentamicin induced renal damage and oxidative stress in rats. Life Sci 2003;73:2543-56

29. Yanagida C, Ito K, Komiya I, Horie T. Protective effect of fosfomycin on gentamicin-induced lipid peroxidation of rat renal tissue. Chem Biol Interact 2004;148:139-47.

30. Abdel-Raheem IT, El-Sherbiny GA, Taye A. Green tea ameliorates renal oxidative damage induced by gentamicin in rats. Pak J Pharm Sci 2010;23:21-8.

31. Schortgen F, Lacherade JC, Bruneel F, Cattaneo I, Hemery F, Lemaire F, et al. Effects of hydroxyethylstarch and gelatin on renal function in severe sepsis: A multicentre randomised study. Lancet 2001;357:911-6.

32. Morin JP, Thomas N, Toutain H, Borghi H, Fillastre JP. Modulation of gentamicin nephrotoxicity by chronic inhibition of angiotensin-Iconverting enzyme in rat. Arch Toxicol 1989;63:47-53.

33. Luft FC, Aronoff GR, Evan AP, Connors BA, Weinberger MH, Kleit SA, et al. The renin-angiotensin system in aminoglycoside-induced acute renal failure. J Pharmacol Exp Ther 1982;220:433-9.

34. Hirth-Dietrich C, Stasch JP, Ganten D, Luft FC. Renal effects of captopril and nitrendipine in transgenic rats with an extra renin gene. Hypertension 1994;23:626-31.

35. Patzer L. Nephrotoxicity as a cause of acute kidney injury in children. Pediatr Nephrol 2008;23:2159-73. 